\title{
The Semantic Web and Networked Governance: Promise and Challenges
}

\author{
Jane E. Fountain \\ National Center for Digital Government \\ University of Massachusetts at Amherst \\ fountain@polsci.umass.edu
}

\begin{abstract}
The virtual state is a metaphor meant to draw attention to the structures and processes of the state that are becoming increasingly aligned with the structures and processes of the semantic web. Semantic Web researchers understand the potential for information sharing, enhanced search, improved collaboration, innovation, and other direct implications of contemporary informatics. Yet many of the broader democratic and governmental implications of increasingly networked governance remain elusive, even in the world of public policy and politics.

Governments, not businesses, remain the major information processing entities in the world. But where do they stand as knowledge managers, bridge builders and creators? As they strive to become not simply information-based but also knowledge-creating organizations, public agencies and institutions face a set of striking challenges. These include threats to privacy, to intellectual property, to identity, and to traditional processes of review and accountability. From the perspective of the organization of government, what are some of the key challenges faced by governments as they seek to become networked? What best practices are emerging globally? And in the networked world that is rapidly emerging and becoming institutionalized, how can public, private and nonprofit sectors learn from one another?
\end{abstract}

\section{About the Speaker}

Jane E. Fountain is Professor of Political Science and Public Policy and the Director of the Center for Public Policy and Administration at the University of Massachusetts Amherst. She is also the founder and director of the National Center for Digital Government which was established with support from the National Science Foundation to build research and infrastructure in the field of research on technology and governance.

Fountain is the author of Building the Virtual State: Information Technology and Institutional Change (Brookings Institution Press, 2001) which was awarded an Outstanding Academic Title in 2002 by Choice. The book has become a classic text in the field and has been translated into and published in Chinese, Japanese and Portuguese. Fountain is currently researching the successor volume to Building the Virtual State, which will examine technology-based 
cross-agency innovations in the U.S. federal government and their implications for governance and democratic processes, and Women in the Information Age (to be published by Cambridge University Press), which focuses on gender, information technology, and institutional behavior.

Professor Fountain also directs the Science, Technology, and Society Initiative (STS) and the Women in the Information Age Project (WITIA). The STS Initiative serves as a catalyst for collaborative, multi-disciplinary research partnerships among social, natural and physical scientists. WITIA examines the participation of women in computing and information-technology related fields and, with its partner institutions, seeks to increase the number of women experts and designers in information and communication technology fields.

She has served on several governing bodies and advisory groups in the public, private and nonprofit sectors in the U.S. and abroad. Her executive teaching and invited lectures have taken her to several developing countries and governments in transition including those of Saudi Arabia, the United Arab Emirates, Nicaragua, Chile, Estonia, Hungary, and Slovenia as well as to countries including Japan, Canada, New Zealand, Australia and the countries of the European Union. 